\title{
EFL Teachers' Perceptions of Classroom Writing Assessment at High Schools in Central Vietnam
}

\author{
Thuy Ho Hoang Nguyen \\ University of Foreign Languages, Hue University, Vietnam \\ Anh Thi Truong \\ Cam Lo High School, Quang Tri, Vietnam
}

\begin{abstract}
This study aimed to explore EFL teachers' perceptions of classroom writing assessment at high schools in Central Vietnam. The constructs of teachers' perceptions under survey included the purposes and procedures employed in classroom writing assessment. Data was collected from an online questionnaire delivered to 60 EFL teachers from different high schools in Central Vietnam, followed by individual in-depth interviews with 10 participants selected from the surveyed teachers. Empirical data generally disclosed the teachers' positive perceptions of the investigated aspects and highlighted both compromise and conflict in teachers' perceptions. The study revealed that formative assessment purposes were associated with the essence of those in summative assessment. Specifically, while formative assessment purposes such as modifying and improving teaching and learning were perceived as important, the teachers also confirmed the necessity of summative assessment purposes of scoring students' writings and ranking students as part of teachers' responsibilities. The study also indicated the teachers' preference for different procedures including setting and informing criteria to students, using diverse assessment methods, and giving diagnostic feedback on student writing. Nonetheless, while the teachers did not highly value writing tests and aimed for the use of various assessment methods, they seemed to have minimal knowledge of alternative assessment, which might adversely affect their intention of diversifying their writing assessment practice. The findings imply the dominance of testing culture and also shed light on the essential role of teacher professional development, particularly in assessment, for effective implementation of classroom writing assessment.
\end{abstract}

Index Terms-EFL classroom writing assessment, teacher perceptions, writing assessment purposes, writing assessment procedures, alternative assessment

\section{INTRODUCTION}

A huge reform in language curriculum design and teaching and assessment practice has been made since the National Foreign Languages Project was launched by Vietnam's Ministry of Education and Training (MOET). In terms of English testing and assessment, it is compulsory that the assessment of four language skills namely reading, listening, speaking and writing be conducted at school of all levels (MOET, 2014) in order for students to achieve Level 3 (equivalent to B1-CEFR) when completing their high school education (Hoang et al., 2014). In accordance with its aim of innovation, the assessment of four language skills should be taken into consideration. Nevertheless, Vietnam high school teachers keep using summative tests mainly to generate marks for ranking students and reporting to parents and to prepare for standardized examinations, which reflects the reality of teaching to the tests (Le, 2015); therefore, assessing language skills is often ignored and how to assess writing effectively receives little attention. Besides, some teachers hold the belief that assessing writing means giving learners a topic to write about and then marking their papers (Le, 2015). Yet writing assessment is not that simple. Khongput (2010) asserts writing as "an art" which requires "the mixture of criteria, judgment and experience" as an assessment method (p. 7). It is even more demanding when writing assessment aims to enhance the teaching and learning of writing. Numerous studies have been conducted to examine teachers' perceptions of writing assessment in several EFL contexts worldwide (e.g., Crusan et al., 2016; Ketabi, 2015; Kobra \& Hossein, 2018; Guadu \& Boersma, 2018; Lee \& Coniam, 2013) whilst this research area has been minimal in Vietnam high schools where testing culture is still dominant (Le, 2015) even though policy-makers have introduced a culture of assessment to improve teaching and learning (Hoang, 2014; MOET, 2014). The current study was therefore an attempt to investigate teachers' perceptions of EFL writing assessment at high schools in Central Vietnam, specifically focusing on the purposes and procedures of classroom writing assessment.

\section{LITERATURE REVIEW}

\section{A. The Concept of Assessment}

The meaning of the term assessment is not generally straightforward and is sometimes misunderstood. Testing and assessing may be mistakenly considered synonymous terms while in fact they are not (Brown, 2004). According to Cizek (1997), assessment is the process of gathering and synthesizing information relevant to the purposes of 
discovering and documenting students' strengths and weaknesses, planning and enhancing instruction, or evaluating progress and making decisions about students. Meanwhile, Brown (2004) sees tests as an instrument that requires the performance of test takers on particular language skills or areas and offers them some kind of result. It can be inferred from these definitions that tests are a subset of assessment and only one of different ways that teachers can use to assess students. At the classroom level, assessment is more associated with the teaching-learning process (Cizek, 1997); in other words, it is employed to promote teaching and learning. As Witte (2012) points out "assessment is most effective and useful when it matches with the instructional content that is taught in the classroom, thereby providing instructionlearning-assessment alignment" (p. 12).

\section{B. Categories of Language Assessment}

Language assessment can be categorized in terms of purposes, intention, interpretation, and in comparisons between traditional assessment and alternative assessment.

Assessment can be used for formative and summative purposes. Formative assessment aims to provide learners and instructors with information on learners' present performance to improve it in the future (Andrade \& Cizek, 2010). Brown (2004) emphasizes that the key to such information is delivering immediate and appropriate feedback on performance, with an eye toward the future continuation of learning, which contributes to the ongoing development of learners' language. Summative assessment differs from formative assessment in a fundamental way; it aims to measure or summarize student's achievement at the end of a course or unit of instruction (Brown, 2004).

Concerning intention, assessment can occur spontaneously or be planned. When it occurs incidentally, it is informal assessment. Teacher's informal assessment is embedded in classroom tasks to elicit student performance such as marginal comments on papers or essay drafts, or suggestions for a strategy without contributing directly to final grades (Brown, 2004). On the other hand, formal assessment is systematic and intended, with the intention to give an appraisal of student achievement, and is generally accompanied by a numerical score.

The interpretation of assessment results may be norm-referenced or criterion-referenced. Norm-referenced assessment ranks learners in comparison with each other (Brindley, 2001), thereby allowing educators to make comparative decisions. Criterion referencing, on the contrary, describes learner performance in relation to an explicitly stated standard, or the level that he/she must reach (Brindley, 2001). Criterion-referenced assessment evaluates students' mastery of course objectives, usually involves students in a class, and connects to a curriculum; hence teachers are required to deliver useful feedback to students to address the gaps in their knowledge (Brown, 2004).

Over the last decades, limitations have been reported to exist in traditional testing, such as concentrating principally on some basic skills, the mismatch between test content and instruction, the overemphasis on discrete skills, and so forth (Herman et al., 1992). The recognition of these shortcomings has given rise to the concept of alternative assessment. Alternative assessment is defined as the ongoing process involving students and teachers in making judgments about the students' progress in nonconventional strategies (Hancock, 1994). Its purpose is to gather data about how students are processing and completing authentic tasks in the target language (Coombe et al., 2012). The characteristics of alternative assessment are summarized as follows: (1) documenting students' growth over time; (2) emphasizing students' strengths; (3) considering the learning styles, language proficiency, cultural and educational backgrounds, and grade levels of students; and (4) authenticity because it reflects tasks typical of real-life settings (Coombe et al., 2012). Alternative assessment, therefore, takes a completely different approach from traditional assessment. Popular forms of alternative assessment include self-/peer-assessment, portfolios, and journals.

\section{EFL Writing Assessment}

English writing in many ways is perceived as the most difficult language skill in comparison with the others. Writing requires a higher level of productive language control (Hyland, 2003) and functions to reinforce patterns of oral language use, grammar and vocabulary (Weigle, 2002). Hamp-Lyons (2003) also claims, "writing is a very complex activity involving thinking, planning, organizing, and linking as well as several levels of language manipulation" (p. 163). Such complex nature of writing poses many challenges faced by not only EFL learners but also teachers as writing assessors.

In teaching and assessing writing, the product and process approaches see writing in different perspectives. The product approach focuses on the learner's final product with error-free performance (Nunan, 1999). This means the written product must be a grammatically correct and coherent text, with appropriate use of vocabulary, grammar, and language devices. The product approach places the emphasis on accurate language form in the final text while the process approach concerns more on the process of how students develop and formulate ideas into effective writing works. The process approach sees writing as a non-linear sequence in which learners go recursively through such stages as planning, drafting, editing, revising, and publishing, and it puts special emphasis on audience and interaction with peers and teachers (Hyland, 2003). In the product approach, students are often passive recipients of information, whereas in the process approach, they become an active part of learning process, develop knowledge under the guidance of teachers and peers, and learn from their mistakes to achieve a longlasting improvement. However different these explanations are, it is worth noting that a good product depends on good process and the emphasis shifts from the final product to the process of creating the final product. 
In assessing students' writing, to avoid bias and subjectivity from raters and to yield consistent scores, there needs to be a systematic process and a written rubric that outlines the criteria for grading. Crusan (2010) highlights that the criteria for writing assessment should be stated clearly in the language that students understand. The best known scoring framework developed by Jacob et al. (1981) presents a set of criteria for assessing compositions including content, organization, vocabulary, language use, and mechanics. However, the number and weight of criteria to evaluate written products depends on the construct of the writing task or the aspects that teachers want to assess their students (Phan, 2008). Therefore, it is important to identify the construct and establish a proper set of criteria before conducting assessment. More importantly, in classroom assessment, in order to obtain positive washback, clear scoring criteria should be informed to both teachers and learners (Phan, 2008).

Unquestionably, timed impromptu writing tests which mainly focus on written products are not sufficient to enhance student writing process. In class, students engage in social interaction with the teacher and peers, and get assistance from them. Therefore, Lee (2017) claims that feedback delivered during different stages of writing process "lies at the heart of classroom writing assessment" (p. 14). In the same manner, the importance of feedback is stressed by Hattie and Timperley (2007) that "feedback is one of the most powerful influences on learning and achievement, but this impact can be either positive or negative" (p. 81). Hattie and Timperley (2007) suggest that effective feedback can be divided into three stages, feed up (Where am I going?), feedback (How am I going?), and feed forward (Where to next?). In the feed up stage, the teacher shares learning goals and success criteria with students and provides instructional scaffolding. In the feedback stage, descriptive and diagnostic feedback linked to criteria given beforehand is delivered to students. This second stage informs students of what progress they are making toward the goal. The last stage, feed forward, provides information about what students need to do next in order to move forward in their learning. In other words, feedback may affect learners on both sides, thus how to deliver feedback effectively is a key question to answer.

Feedback on student writing can come from both teachers and students. Hyland (2003) points out that teachers' response to their students' writing is in various forms, such common ones as commentary, rubrics, minimal marking, and electronic feedback. Bloxham and Boyd (2007) strongly assert that written feedback needs "to provide specific and sufficient comments and suggestions on strengths, areas for development, and strategies for improvement" (p. 104). Lee (2017) also suggests using feedback to diagnose students' strengths and weaknesses. In other words, teachers should use feedback to inform students of their major strengths and areas for improvement with reference to the learning goals and success criteria. Additionally, peer feedback is used synonymously with peer response or peer assessment, which has potential in developing student writing ability through creating meaningful interaction among peers (Lee, 2017). Andrade and Cizek (2010) state that students prefer feedback provided by peers rather than teachers, because peer feedback can be more immediate, timely and individualized. Lee (2017) stresses that if students engage in peer feedback meaningfully, not only do they help their peers to improve their writing but they also enhance their ability to review, critique, and improve their own writing. On the negative side, according to Hyland (2003), learners are rhetorically inexperienced, so they may focus more on sentence level than ideas and organization, which makes their feedback somewhat unhelpful. However, Penaflorida (2002) argues that students may not be as skilled as their teachers at responding to each other's works, but "they are excellent in providing the one thing that writers need most - an audience" (p. 351).

Along with teacher feedback and peer feedback, feedback from students themselves is important in life-long learning; self-assessment of one's own writing is, therefore, considered "a step toward learner autonomy" (Penaflorida, 2002, p. 351). Research shows that students are capable of analyzing and responding to their own writing, thus by letting students react to their own writing, they will become independent learners (Iraji et al., 2016). Alternative assessments such as portfolios and journals can be involved to assess both the process and the product of students' writing (Coombe et al., 2012; Hancock, 1994).

\section{Review of Studies on EFL Writing Assessment}

The issues around writing assessment have inspired numerous researchers worldwide. A number of previous studies have examined certain aspects concerning teachers' perceptions and practice of EFL writing assessment. A large-scale survey throughout 41 EFL/ESL countries conducted by Crusan et al. (2016) revealed that the teachers had little training in alternative assessment and felt confused in the use of rubrics in writing classes. In Lee and Coniam's (2013) study, while the teachers were committed to and enthusiastic about assessment for learning (AfL) in teaching writing, they had to adhere to conventional practices. The study indicated that the test-oriented system that valued summative scores could pose severe obstacles to the implementation of AfL in writing at secondary schools in Hong Kong. A more recent research by Guadu and Boersma (2018) showed that the instructors' positive beliefs about formative assessment and their actual practices were incongruent in Ethiopian context. Likewise, alternative assessments have become the issues of interest among researchers (e.g. Birjandi \& Hadidi Tamjid, 2012; Eridafithri, 2015; Iraji et al., 2016; Ketabi, 2015; Kobra \& Hossein, 2018; Vangah et al., 2016). These studies implied that alternative assessments had a significant effect on student writing ability; however, there remain difficulties in implementing them. Some studies conducted in Vietnam have dealt with rater consistency in essay evaluation (e.g., Nguyen, 2016) and self-assessment in writing classes (e.g., Nguyen, 2015).

Although writing assessment has increasingly gained attention, the existing research literature has three major limitations. First, it can be noted that most of the aforementioned studies have been conducted in tertiary education 
contexts where teachers tend to have higher qualifications; consequently, their perceptions might greatly differ from those in high school education settings. Undoubtedly, responses to the same questions in different contexts might vary; what underpins previous findings and what underlies the remaining issues are still unexplored. Second, while numerous assessment-related activities have been discussed, there exist considerable debates over teachers' views in different settings. Ultimately, it is problematic that few studies provide empirical evidence of how EFL teachers understand purposes and procedures employed in classroom writing assessment in the context of Vietnam where there has been a huge reform in curriculum design, textbook, teaching and assessment (Hoang, 2015). In response to the need for further research of this area, the current study sets out to investigate Vietnamese EFL teachers' perceptions of writing assessment at some high schools in Central Vietnam, a disadvantaged area where research on EFL teaching, learning and assessment has so far been minimal.

\section{ReSEARCH Methodology}

\section{A. Context of the Study}

In accordance with the MOET's (2014) reform whereby the assessment of four language skills, namely reading, listening, speaking, and writing should be conducted at all levels of education, guidelines on how to implement this at high schools were also issued. In other words, the English mid-term tests and end-of-course tests at high schools must include four language skills, one of which is writing. More importantly, the new English textbooks for high school students in Vietnam have been claimed to respond to the MOET's reform in language curriculum design, teaching and assessment practice and to equip learners with four language skills in order to help them develop communicative competence (Hoang et al., 2014).

It can be said that the MOET's policy, the implementation guidelines and the new version of English textbooks have supported EFL teachers in Vietnam to integrate all language skills in teaching, testing and assessment. Nonetheless, time for teaching writing skill is very minimal in practice, let alone that for testing and assessing it. Accordingly, teachers have the tendency to integrate listening, reading, writing and language areas in a mid-term test or an end-ofsemester test lasting for 45 minutes each with the writing section accounting for $20 \%$ of the total mark.

\section{B. Participants}

The current study involved 60 EFL teachers (11 males and 49 females) as participants, who were based at 16 high schools applying the new version of English textbooks in Central Vietnam. The samples' teaching experience ranged from three to over twenty years, with 8 teachers having a Master's degree and 52 obtaining a Bachelor's degree in TEFL (Teaching English as a Foreign Language).

\section{Data Collection}

In order to investigate teachers' perceptions of EFL writing assessment, the study employed questionnaire and interview as data collection instruments. The use of questionnaire is advantageous as it can accommodate a large amount of data which reflects attitudes, beliefs, practices, and trends of the population, and reduces sampling error (Creswell, 2012). Besides, Dörnyei (2007) asserts that a well-conducted interview is a powerful tool to elicit rich data on people's perspectives and attitudes that underpin their behaviours. The study started with the collection and analysis of data from the questionnaire to gain an initial understanding of the research problems and was then followed by indepth interviews to obtain further information, thereby being able to provide full understanding and deep insights into the investigated issues.

The full questionnaire consisted of 16 statements in which 6 items concern teacher perceptions of writing assessment purposes and 10 items inquire teacher perceptions of writing assessment procedures. The questionnaire items were based on the literature and designed in the closed-ended form as it is best for obtaining data that can be easily categorized (McMillan \& Schumacher, 1993). Moreover, scales were used because they are viewed to allow fairly accurate assessments of opinions in terms of gradations (McMillan \& Schumacher, 1993). The teachers were asked to indicate their opinions on a 5 -point Likert scale $(5=$ strongly agree, $4=$ agree, $3=$ undecided, $2=$ disagree, and $1=$ strongly disagree). The questionnaire was written in Vietnamese to ensure clarity of meaning for the participants and distributed online by means of Google form.

After the initial analysis of the questionnaire responses, the interview protocol was designed. Since the interview aimed to clarify the variations in teachers' responses to the questionnaire, most of the interview questions were relevant to the questionnaire items receiving lower mean and/or high standard deviation. Specifically, the interview questions concern the teachers' perceptions of marking and ranking purposes and the procedures of informing criteria, giving marks, making comments, providing feedback, using alternative assessment and using writing tests. The interview questions were designed in the semi-structured form because of its flexibility which allows individual open-ended responses to fairly specific questions (Borg, 2015). The individual interviews were conducted in Vietnamese with 10 teachers. Each individual interview lasted from 20 to 25 minutes and was recorded with the consent of the interviewees. The interview participants' names remained confidential through the use of pseudonyms (Teachers I1-I10) on reporting findings. 


\section{Data Analysis}

Data analysis was presented in accordance with the work aspects under survey, thereby combining the elements of quantitative and qualitative data. Descriptive analysis was employed to transform a set of numbers into indices to describe the questionnaire data. Statistical numbers, including percentages, means and standard deviations were computed. The results were then presented in figures and tables to make the interpretations comprehensible. Following initial analysis of the quantitative data, the interview data was transcribed and analyzed using content analysis (Dörnyei, 2007) that identifies messages to elaborate the questionnaire data in relation to writing assessment purposes and writing assessment procedures.

\section{FINDINGS AND DisCUSSION}

\section{A. Teachers' Perceptions of Writing Assessment Purposes}

This section presents and discusses empirical data about teacher perceptions of writing assessment purposes. The results of questionnaire data are summarized in Table 1.

TABLE 1

Teachers' Perceptions Of Writing Assessment Purposes

( $\mathrm{SA}=$ Strongly Agree, $\mathrm{A}=$ Agree, $\mathrm{U}=$ Undecided, $\mathrm{D}=$ Disagree, $\mathrm{SD}=$ Strongly Disagree, $\mathrm{M}=\mathrm{Mean}, \mathrm{Std}$ Dev $=$ Standard Deviation $)$

\begin{tabular}{|c|c|c|c|c|c|c|c|}
\hline Statements & $\begin{array}{c}\mathrm{SA} \\
\%\end{array}$ & $\begin{array}{l}\mathrm{A} \\
\%\end{array}$ & $\begin{array}{l}\mathrm{U} \\
\%\end{array}$ & $\begin{array}{l}\mathrm{D} \\
\%\end{array}$ & $\begin{array}{c}\mathrm{SD} \\
\%\end{array}$ & $\mathrm{M}$ & $\begin{array}{l}\text { Std. } \\
\text { Dev. }\end{array}$ \\
\hline $\begin{array}{l}\text { 1. Assessing students' writing is conducted as part of teaching and } \\
\text { learning English. }\end{array}$ & 50.0 & 43.3 & 3.3 & 3.3 & 0.0 & 4.40 & 0.72 \\
\hline 2. Assessment is conducted to mark students' writing. & 11.7 & 51.7 & 25.0 & 8.3 & 3.3 & 3.60 & 0.92 \\
\hline $\begin{array}{l}\text { 3. Assessment is conducted to evaluate students' mastery of course } \\
\text { objectives. }\end{array}$ & 43.3 & 41.7 & 10.0 & 3.3 & 1.7 & 4.22 & 0.88 \\
\hline 4. Assessment is conducted to rank students. & 11.7 & 51.7 & 25.0 & 8.3 & 3.3 & 3.60 & 0.92 \\
\hline 5. Assessment is conducted to modify on-going teaching. & 51.7 & 35.0 & 10.0 & 3.3 & 0.0 & 4.35 & 0.80 \\
\hline 6. Assessment is conducted to improve learning process. & 41.7 & 41.7 & 15.0 & 1.7 & 0.0 & 4.23 & 0.77 \\
\hline
\end{tabular}

As Table 1 indicates, most of the items were rated positively and the proportions of respondents rating strongly disagree and disagree were conspicuously low, which reveals that the surveyed teachers attached importance to the purposes of writing assessment mentioned. Item 1 as a general statement introducing how teachers perceived writing assessment as part of teaching and learning English received the highest mean value $(\mathrm{M}=4.40)$ with $93.3 \%$ of the participants who either agreed or strongly agreed with the statement. Similarly, a noticeable trend would be claimed from items $5(M=4.35)$ and $6(M=4.23)$ that the vast majority of participants $(86.7 \%$ and $83.4 \%$ respectively) believed that assessing writing played a pivotal role in teaching and learning, that is to modify on-going teaching and improve learning process. This claim is also evidenced in item $3(\mathrm{M}=4.22)$ wherein most of the informants $(85.0 \%)$ assumed that writing assessment is conducted to evaluate students' mastery of the course objectives. These findings reflect the teachers' positive attitudes towards the formative purposes of writing assessment, which coincides exactly with what Guadu and Boersma (2018) and Lee and Coniam (2013) already emphasized in their previous research.

Another feature worthy of commenting is teachers' perspectives on whether assessing writing is conducted to mark students' writing or to rank students. As illustrated in Table 1, the number of teachers responding to items 2 and 4 was exactly the same at each of the 5 points on Likert scale. Hence, there is a noticeable variation among teachers' responses to both items 2 and $4(\mathrm{M}=3.60$, Std. Dev.=0.92). Figure 1 illustrates clearly the proportions of the teachers' responses to both items 2 and 4 with reference to the levels of agreement.

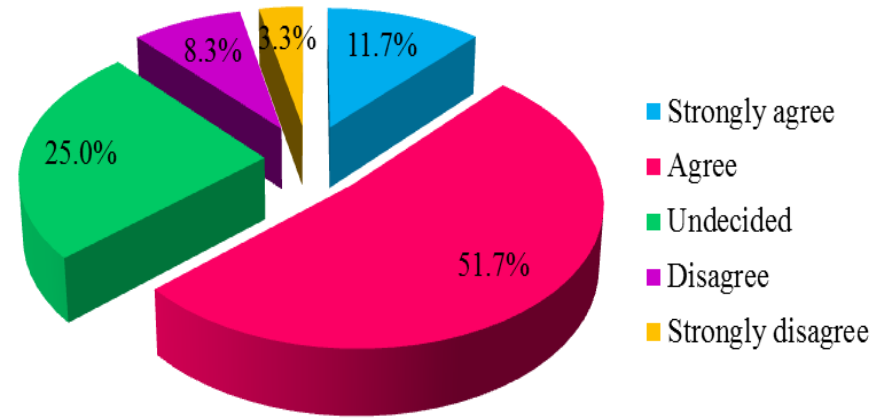

Figure 1. Teachers' perception of whether assessment is conducted to mark students' writing Teachers' perception of whether assessment is conducted to rank students

It is obvious from Fig. 1 that more than half of the participants $(63.4 \%)$ thought that assessment is conducted to mark students' writing as well as rank students while a quarter of them $(25 \%)$ were uncertain about their answer and the rest 
$(11.6 \%)$ disagreed with the statements. In other words, more participants considered the purposes of marking and ranking important, whereas a remarkably lower number of the teachers $(36.6 \%)$ kept mixed feelings or opposed to the ideas. Notably, items 2 and 4 received the lowest mean score compared to the others; it would thus be reasonable to claim that the teachers viewed the purposes of marking and ranking not as important as those indicated in items $1,3,5$, and 6. This finding was subsequently clarified by the interview results. When being interviewed, the teachers highlighted the compulsion of marking writings in order to rank students, yet emphasized that assessing writing also served many other purposes such as to see student learning ability and to modify their teaching methods. They made the following assertions:

I think scores are not the most important; however, it is necessary because giving marks to students' works is compulsory. Also, marks are necessary in classifying or ranking students. Therefore, that assessing writing serves the purposes of marking and ranking is not an exception. (Teacher I1)

It depends. Marking is necessary when teachers need to provide scores for students' work. They can also be ranked according to their scores. In addition, thanks to the assessment of students' writing performance, teachers can see students' levels, and sort out some ways to fill their knowledge gaps as well as modify lesson plans. (Teacher I4)

We rarely have time to conduct writing assessment in reality. Normally, writing assessment is included in the progress tests, mid-term tests or end-of-semester tests. As a result, scores are always required. (Teacher I6)

The findings from questionnaire and interviews not only indicate the teachers' emphasis on the relationship between marking and ranking but also disclose the teachers' understanding of writing assessment purposes, which are to enhance teaching and learning writing in addition to evaluating students' knowledge, in other words, giving priority to formative assessment purposes. The findings are consistent with those found in a number of earlier studies whereby EFL teachers had positive attitudes towards the important roles of formative assessment in the teaching and learning of writing skill (e.g., Guadu \& Boersma, 2018; Lee \& Coniam, 2013). These results also support the idea that assessment should be employed to promote teaching and learning; particularly, in classroom-based assessment, formative assessment is prominent because it contributes to the ongoing development of learners' language (Brown, 2004; Witte, 2012). Furthermore, writing by nature is considered a demanding language skill, thus integrating assessment into instruction to enhance teaching and learning writing should be highly appreciated. Since writing skill is required to be included in English tests at high schools (MOET, 2014) and time for classroom writing assessment is limited, the findings highlighted how teachers made compromise in their own perceptions, that is, they appreciated the formative purposes of writing assessment while still confirming the summative purposes such as marking and ranking students as part of the teachers' responsibilities.

\section{B. Teachers' Perceptions of Writing Assessment Procedures}

This section analyzes and discusses how high school EFL teachers perceived the procedures that should be followed in classroom writing assessment. In general, the data analysis shows relative consistencies in teachers' responses. Fig. 2 below shows the teachers' agreement and disagreement levels across the facets including defining construct, setting criteria, informing criteria, informing progress, giving comments, giving diagnostic feedback, aligning feedback with criteria, using different methods, using alternative assessment, and using writing tests.

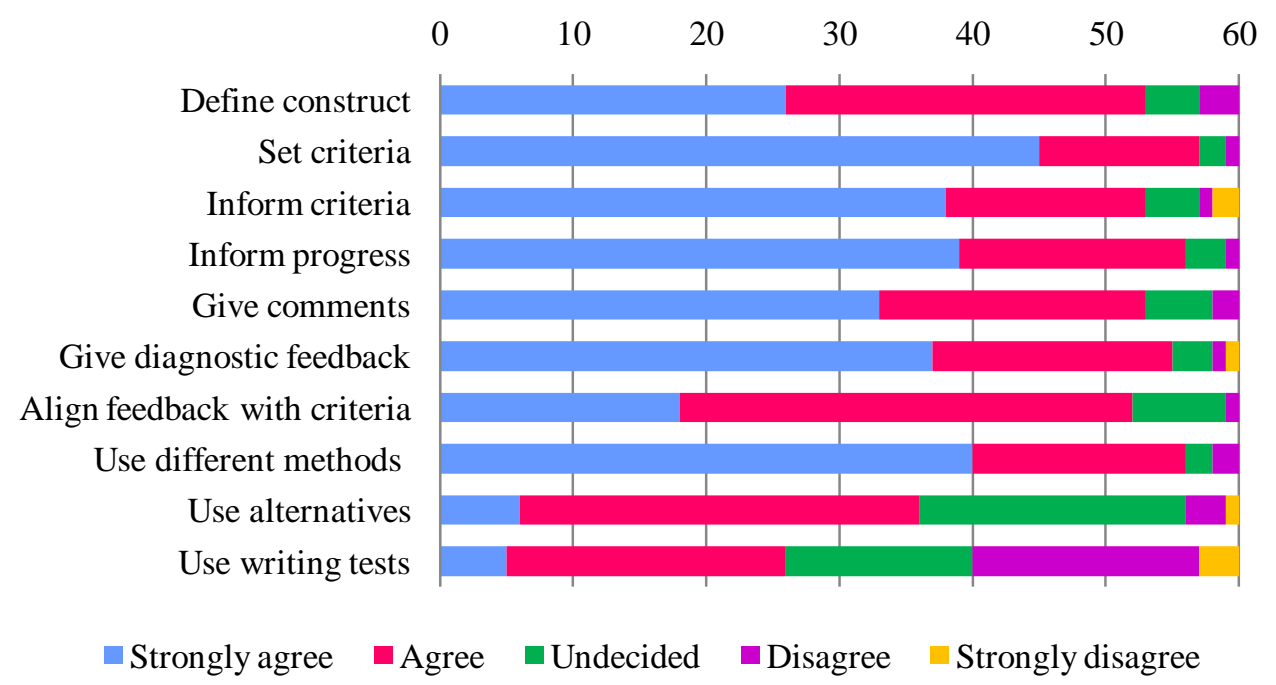

Figure 2. Teacher perceptions of writing assessment procedures

As displayed in Fig. 2, the participants reach high agreement on the listed aspects while the levels of disagreement are noticeably low. This generally discloses the teachers' positive attitudes towards the listed procedures. It can be 
observed from Fig. 2 that agreement rating is the highest at setting criteria and lowest at using writing tests. Table 2 details percentages, means, and standard deviations of the responses to every single item.

TABLE 2

TEACHERS' PERCEPTIONS OF Writing ASSESSMENT PROCEDURES

( $\mathrm{SA}=$ Strongly Agree, $\mathrm{A}=$ Agree, $\mathrm{U}=$ Undecided, $\mathrm{D}=$ Disagree, $\mathrm{SD}=$ Strongly Disagree, $\mathrm{M}=$ Mean, Std Dev = Standard Deviation)

\begin{tabular}{|c|c|c|c|c|c|c|c|}
\hline Statements & $\begin{array}{c}\text { SA } \\
\%\end{array}$ & $\begin{array}{l}\mathrm{A} \\
\%\end{array}$ & $\begin{array}{l}\mathrm{U} \\
\%\end{array}$ & $\begin{array}{l}\mathrm{D} \\
\%\end{array}$ & $\begin{array}{c}\text { SD } \\
\%\end{array}$ & $\mathrm{M}$ & $\begin{array}{c}\text { Std } \\
\text { Dev }\end{array}$ \\
\hline 7. Teachers should define the construct when assessing writing. & 43.3 & 45 & 6.7 & 5.0 & 0.0 & 4.27 & 0.80 \\
\hline 8. Teachers should set criteria to evaluate students' writing. & 75.0 & 20.0 & 3.3 & 1.7 & 0.0 & 4.68 & 0.62 \\
\hline 9. Teachers should inform students of the assessment criteria beforehand. & 63.3 & 25.0 & 6.7 & 1.7 & 3.3 & 4.43 & 0.95 \\
\hline 10. Teachers should inform students of the progress they make in writing process. & 65.0 & 28.3 & 5.0 & 1.7 & 0.0 & 4.57 & 0.67 \\
\hline 11. Teacher should give comments rather than marks on students' writing. & 55.0 & 33.3 & 8.3 & 3.3 & 0.0 & 4.40 & 0.79 \\
\hline 12. Teachers should give diagnostic feedback for students to realize their strengths and weaknesses. & 61.7 & 30.0 & 5.0 & 1.7 & 1.7 & 4.48 & 0.81 \\
\hline 13. Teachers should align feedback with the assessment criteria already set. & 30.0 & 56.7 & 11.7 & 1.7 & 0.0 & 4.15 & 0.68 \\
\hline 14. Teachers should use different methods for assessing writing. & 66.7 & 26.7 & 3.3 & 3.3 & 0.0 & 4.57 & 0.72 \\
\hline 15 Teachers should use alternatives for assessing writing. & 10.0 & 50.0 & 33.3 & 5.0 & 1.7 & 3.62 & 0.80 \\
\hline 16. Teachers should use writing tests to obtain a good estimate of students' writing ability. & 8.3 & 35.0 & 23.3 & 28.3 & 5.0 & 3.13 & 1.08 \\
\hline
\end{tabular}

As depicted in Table 2, the most dominant trend is that almost all surveyed teachers proclaimed the importance of setting criteria in writing assessment. As illustrated in item $8(\mathrm{M}=4.68)$, up to $75.0 \%$ of the participants showed their strong agreement, gaining the highest figure across this column and $20 \%$ of them agreed with setting criteria for evaluating students' writing. In addition, a large proportion $(88.3 \%)$ of the respondents contended that teachers should inform students of the criteria before conducting an assessment (item 9, M=4.43). Although there are still proportions of disagreement $(1.7 \%)$ and strong disagreement $(3.3 \%)$, these numbers are not considerable. That agreement rates far outweigh disagreement ones indicates that most participants held positive perceptions about informing students of the assessment criteria. This finding was evidently supported by interview results. All interviewees stated that teachers should set and discuss criteria with students beforehand because this helped teachers make fair evaluations and focused students' attention on what to write and how to meet the expected requirements. As a result, from the teachers' perspectives, mastering assessment criteria is of great importance to both teachers and learners. This confirms the assertions of many researchers (e.g. Hattie \& Timperley, 2007; Khongput, 2010; Lee, 2017; Phan, 2008) that in classroom assessment, clear criteria should be provided for both teachers and learners in order to obtain positive washback; once students are aware of success criteria and learning goals, they will be able to assess their own progress and understand what they can do to improve their future writing.

Concerning defining language construct prior to conducting writing assessment, item $7(\mathrm{M}=4.27)$ shows $88.3 \%$ of the participants expressing their agreement, wherein there is no response to strong disagreement. In other words, a large number of the respondents acknowledged the necessity of defining what construct to assess writing. As discussed in the literature, defining construct is significant because it equips teachers with what aspects of writing to be assessed, from which they can set criteria to evaluate students' writing (Phan, 2008).

Informing progress and giving feedback were also well perceived by the participants. As analyzed in item 10 $(\mathrm{M}=4.57)$, the overwhelming majority $(93.3 \%)$ of them reached agreement on informing students of their progress in the writing process. The claim is also strongly supported by item $11(\mathrm{M}=4.40)$ in which teacher participants expressed their interest in giving comments rather than marks on students' works, at $88.3 \%$ agreement. In responding to the question which asks teachers to identify whether giving marks or giving comments is better, one interviewee asserted as follows:

Psychologically, it is students' interest and habit to see how many marks they get whenever receiving their writing papers. However, giving feedback is far better to help improving student writing proficiency because detailed comments help them realize strong and weak points and make improvements next time. (Teacher I7)

Moreover, the principles of giving effective feedback must be well noted when items $12(\mathrm{M}=4.48)$ and $13(\mathrm{M}=4.15)$ gain up to $91.7 \%$ and $86.7 \%$ of participants' agreement, respectively. These figures imply that the teachers strongly agreed that they should give diagnostic feedback to help students realize their strengths and weaknesses, and align feedback with the criteria established beforehand. These results are consistent with the relevant literature; that is, feedback should be concretely and constructively delivered by integrating with the planned criteria to inform students of their major strengths and areas for improvement (Bloxham \& Boyd, 2007; Hattie \& Timperley, 2007; Lee, 2017).

Given that giving feedback and informing progress are formative by nature, this ample evidence elaborates on the earlier finding of the current study; that is, the teachers highly appreciated the formative purposes of writing assessment.

In addition, the teachers' perceptions were well reflected in item $14(\mathrm{M}=4.57)$, in which the vast majority $(93.4 \%)$ of them agreed that they should use diverse methods to assess writing. This anticipation is also reflected in item 16 $(\mathrm{M}=3.13, \mathrm{SD}=1.08)$ where many participants did not believe that writing tests can provide a good estimate of writing ability as shown by the lowest agreement rate at only $43.3 \%$. Interviewees expressed that they should assess student 
ability by various ways because writing tests had many shortcomings such as limited topics, mark focus, and being conducted under time pressure. Concerning if tests should be used to assess students' writing ability, one teacher articulated her opinion:

Writing tests may bring about unreliable results because of both subjective and objective factors such as inappropriate topics, health problems, and limited time, so writing tests are not the best to evaluate student writing ability. (Teacher I3)

Much in the same vein, another teacher added:

Tests focus on marks, so students cannot always see their strengths and weaknesses and teachers may not motivate weak students in learning writing as well. (Teacher I2)

The participants were, therefore, not completely supportive of using tests in assessing writing. Likewise, traditional tests are frequently criticized for their time-related constraints and therefore cannot assess the depth of a student's knowledge (Brown, 2004). As Brown (2004) states, all methods could be beneficial, but using one method instead of a variety of methods could not help in building student proficiency. In other words, different methods for assessing should be employed.

Unexpectedly, the reflection above seems not consistent with the responses to item $15(\mathrm{M}=3.62)$ which has a remarkably lower mean score than item $14(\mathrm{M}=4.57)$ at 0.95 . One third of informants $(33.3 \%)$ neither agreed nor disagreed that alternatives should be used in assessing writing. This could probably be the tendency of being neutral or avoiding expressing opinions when participants were not confident about their answers, which implies their insufficient understanding of alternative assessment. Interview data reveal while the teachers believed that tests are not the only way to assess students' writing ability, some teachers seemed unfamiliar with specific terminologies associated with alternative assessment as few interviewees mentioned other ways in writing instruction (e.g. portfolios, journals, selfassessment). In addition, some teacher interviewees felt uncertain about the benefits of alternative assessment because they strongly believed that portfolios, journals, and self-assessment were suitable for only good students.

It is argued that alternatives compensate for shortcomings of timed tests because they add more tools to measure students' abilities and contribute to students' development of language skills (Brown, 2004; Weigle, 2002). In the same line, Brown and Hudson (1998) vehemently claim that alternative assessment requires students to use real-world tasks, assess their true abilities, focus on process, employ problem-solving skills, and provide information about their strong and weak points. Many studies have also proved significant effects of portfolios, self-/peer assessment, and journals on improving student writing (Birjandi \& Hadidi Tamjid, 2012; Iraji et al., 2016; Kobra \& Hossein, 2018; Vangah et al., 2016). The teachers' reflection in the current study, however, is inconsistent with what has been found in previous research. A relatively substantial proportion of the teachers $(40 \%)$ were either doubtful or against the use of alternative assessment, some teachers even questioned its usefulness for students of lower levels. This finding highlights an interesting conflict within the teachers' perceptions, that is, while they did not highly value the role of writing tests and thus emphasizing the necessity of employing different methods for assessing writing, they were not really confident in making use of alternative assessment in order to diversify their writing assessment practice.

\section{CONCLUSION}

The study highlighted the teachers' positive perceptions of EFL writing assessment. Overall, the vast majority of the teachers had positive perceptions of the purposes of EFL writing assessment, agreeing that writing assessment is conducted to promote the teaching and learning of writing. Importantly, the findings implied that the purposes of formative assessment were preferred, which is similar to EFL teachers' views in different contexts of previous research; nonetheless, in the current study, the formative purposes were associated with the essence of those in summative assessment and the teachers saw grading as one of their teaching responsibilities. The procedures employed in classroom writing assessment were also well acknowledged. Particularly, the teachers expressed their high agreement on setting and informing criteria to students, using diverse assessment methods, and giving diagnostic feedback on student writing. However, while the teachers did not highly appreciate writing tests and aimed for the use of different assessment methods, they seemed to have limited awareness and inadequate knowledge of alternative assessment, which indicates a conflict in teachers' perceptions and might adversely affect their assessment practice. This finding is likely to contradict the results of previous research whereby alternative assessment is highly appreciated.

In general, by employing multiple methods of data collection, the study achieved its goals of exploring teachers' perceptions of EFL writing assessment at high schools in Central Vietnam. The findings both confirm and contradict earlier research. The findings also imply that testing culture was still dominant at high schools in Central Vietnam. Tests were still perceived to be mainly employed in assessing writing; therefore, the purposes of scoring and ranking students were confirmed along with other purposes of promoting teaching and learning. Testing culture was also dominant in that although tests were neither well perceived to obtain a good estimate of learners' writing ability nor acknowledged to be the only means to assess learners' writing, a considerable number of teachers were reluctant in recognizing the value of alternative assessment. These findings have made significant contributions to the field of language teaching and assessment and highlighted implications for effective teaching and assessing writing in Vietnamese educational context. 
In order for writing assessment to work effectively, it is imperative to take account of teachers' professional development in assessment in order to build teachers' capacity of improving their assessment practice. Furthermore, relevant reference materials, clear guidelines and instructions should be offered so that teachers should have an unambiguous sense of how to conduct writing assessment-related activities effectively in class. Only when the teachers are equipped with theoretical and practical knowledge of assessment methods do they implement writing assessment successfully in congruence with Vietnamese educational reform.

Admittedly, despite the contributions to the field of EFL writing assessment, some limitations are unavoidable. First, the scale of the study is limited to EFL teachers at only some high schools in Central Vietnam. The second limitation also stems from the participants themselves. The study focused on teachers' perceptions while students' perceptions have not been examined yet. In order to overcome the above shortcomings, possible directions for future research on the nascent issues emerging from EFL writing assessment are suggested. First, a fruitful line for future research might investigate the perceptions and practice of other stakeholders as well as the difficulties they encounter when writing assessment is conducted. Furthermore, a larger-scale study should be considered by future researchers so that a deeper understanding of Vietnamese EFL teachers' perceptions and practice of writing assessment would be gained. In the light of these suggestions, decisions on the reform of language teaching and assessment might be made more valid in the current educational context of Vietnam.

\section{ACKNOWLEDGMENTS}

The authors wish to thank the EFL teachers at the high schools in Central Vietnam who gave their time to complete the survey and take part in the interviews in the data collection of the study.

\section{REFERENCES}

[1] Andrade, H. \& Cizek, G. J. (2010). Handbook of formative assessment. New York: Routledge.

[2] Birjandi, P. \& Hadidi Tamjid, N. (2012). The role of self-, peer and teacher assessment in promoting Iranian EFL learners' writing performance. Assessment \& Evaluation in Higher Education 37.5, 513-533.

[3] Bloxham, S. \& Boyd, P. (2007). Developing effective assessment in higher education: A practical guide. London: McGraw-Hill.

[4] Borg, S. (2015). Teacher cognition and language education: Research and practice (2 ${ }^{\text {nd }}$ edn.). London: Bloomsbury Publishing.

[5] Brindley, G. (2001). Assessment. In R. Carter \& D. Nunan, The Cambridge guide to teaching English to speakers of other languages. Cambridge: Cambridge University Press, 137-143.

[6] Brown, H. D. (2004). Language assessment: Principles and classroom practices. New York: Pearson Education.

[7] Brown, J. D., \& Hudson, T. (1998). The alternatives in language assessment. TESOL Quarterly 32.4, $653-675$.

[8] Cizek, G. J. (1997). Learning, achievement, and assessment: Constructs at a crossroads. In G. D. Phye, Handbook of classroom assessment: Learning, Achievement and Adjustment. California: Academic Press, 2-29.

[9] Coombe, C. Purmensky, K. \& Davidson, P. (2012). Alternative assessment in language education. In C. Coombe, P. Davidson, B. O'Sullivan \& S. Stoynoff, The Cambridge guide to second language assessment. Cambridge: Cambridge University Press, $147-155$

[10] Creswell, J. W. (2012). Educational research: Planning, conducting and evaluating quantitative and qualitative research (4 ${ }^{\text {th }}$ edn.). New Jersey: Pearson Education.

[11] Crusan, D., Plakans, L., \& Gebril, A. (2016). Writing assessment literacy: Surveying second language teachers' knowledge, beliefs, and practices. Assessing Writing 28, 43-56.

[12] Dörnyei, Z. (2007). Research methods in applied linguistics: Quantitative, qualitative, and mixed methodologies. Oxford: Oxford University Press.

[13] Eridafithri, E. (2015). The application of portfolios to assess progress in writing of EFL students at secondary schools in Banda Aceh. Studies in English Language and Education 2.1, 1-15.

[14] Guadu, Z. B., \& Boersma, E. J. (2018). EFL instructors' beliefs and practices of formative assessment in teaching writing. Journal of Language Teaching and Research 9.1, 42-50.

[15] Hamp-Lyons, L. (2003). Writing teachers as assessors of writing. In B. Kroll (Ed.), Exploring the dynamics of second language writing. Cambridge: Cambridge University Press, 162-189.

[16] Hancock, C. R. (1994). Alternative assessment and second language study: What and why? ERIC Digest. https://eric.ed.gov/?id=ED376695 (accessed 15/8/2018).

[17] Hattie, J., \& Timperley, H. (2007). The power of feedback. Review of Educational Research 77.1, 81-112.

[18] Herman, J. L., Aschbacher, P. R., Winters, L. (1992). A practical guide to alternative assessment. USA: University of California.

[19] Hoang, V. V., Hoang, T. X. H., Dang, H. G., Phan, H., Hoang, T. H. H., Kieu, T. T. H., Vu, T. L., Dao, N. L. (2014). Tieng Anh 10 (Teacher book - Volume 1). Ha Noi: Vietnam Education Publishing House.

[20] Hoang, V. V. (2015). The development of the ten-year English textbook series for Vietnamese schools under the National Foreign Language 2020 Project: A cross-cultural collaborative experience. VNU Journal of Science: Foreign Studies 31.3, 1-17.

[21] Hyland, K. (2003). Second language writing. Cambridge: Cambridge University Press.

[22] Iraji, H. R., Enayat, M. J., \& Momeni, M. (2016). The effects of self-and peer-assessment on Iranian EFL learners' agumentative writing performance. Theory and Practice in Language Studies 6.4, 716-722.

[23] Jacobs, H., Zingkgraf, S., Wormuth, D., Hartfiel, V., \& Hughey, J. (1981). Testing ESL composition: A practical approach. Rowley, MA: Newbury House. 
[24] Ketabi, S. (2015). Different methods of assessing writing among EFL teachers in Iran. International Journal of Research Studies in Language Learning 5.2, 3-15.

[25] Khongput, S. (2010). EFL writing assessment practices: Teachers' perspectives. In The $36^{\text {th }}$ International Association for Educational Assessment (IAEA) Annual Conference. Bangkok, Thailand.

[26] Kobra, S., \& Hossein, H. (2018). A comparative study of the effect of portfolio and dialogue journal assessment on Iranian EFL learners' writing performance. Journal of Language Teaching and Research 9.2, 408-417.

[27] Le, N. T. (2015). The contexts of assessment in EFL classrooms in two high schools in Vietnam. Ph.D. dissertation, University of Queensland.

[28] Lee, I. (2017). Classroom writing assessment and feedback in L2 school contexts. Singapore: Springer Nature.

[29] Lee, I., \& Coniam, D. (2013). Introducing assessment for learning for EFL writing in an assessment of learning examinationdriven system in Hong Kong. Journal of Second Language Writing 22.1, 34-50.

[30] McMillan, J. H., \& Schumacher, S. (1993). Research in education: a conceptual introduction ( ${ }^{\text {rd }}$ edn.). New York: Harper Collins

[31] MOET. (2014). Dispatch No. 5333/BGDĐT-GDTrH: Implementing language testing and assessment in order to develop learners' English proficiency at secondary level from academic years 2014-2015. Hanoi.

[32] Nguyen, T. H. T. (2015). An investigation into students' self-assessment practice in writing classes in Quang Binh University. Unpublished Master thesis. Hue College of Foreign Languages, Hue University, Thua Thien Hue, Vietnam.

[33] Nguyen, T. Q. Y. (2016). Rater consistency in rating L2 learners' writing task. VNU Journal of Foreign Studies 32.2, 75-84.

[34] Nunan, D. (1999). Second language teaching and learning. Boston, Mass: Heinle \& Heinle Publishers.

[35] Penaflorida, A. H. (2002). Nontraditional forms of assessment and response to student writing: A step toward learner autonomy In J. C. Richards \& W. A. Renandya, Methodology in language teaching: An anthology of current practice. Cambridge: Cambridge University Press, 344-355.

[36] Phan, S. (2008). Communicative language testing. TESOL Professional Development 6.1, 3-10.

[37] Vangah, F. P., Jafarpour, M., \& Mohammadi, M. (2016). Portfolio assessment and process writing: Its effect on EFL students' L2 writing. Journal of Applied Linguistics and Language Research 3.3, 224-246.

[38] Weigle, S. C. (2002). Assessing writing. Cambridge: Cambridge University Press.

[39] Witte, R. H. (2012). Classroom assessment for teachers. New York: McGraw-Hill.

Thuy Ho Hoang Nguyen has a BA in English Language Teaching from the University of Education, Hue University in Vietnam, an $\mathrm{MA}$ and a $\mathrm{PhD}$ both in Applied Linguistics from the University of Queensland, Australia. She is currently a lecturer at the University of Foreign Languages, Hue University in Vietnam. Dr Nguyen's research interest and publications are mainly in Applied Linguistics and English language education.

Anh Thi Truong has a BA in English Language Teaching and an MA in Theory and Methodology of English language teaching both from University of Foreign Languages, Hue University in Vietnam. She is currently a language teacher at Cam Lo high school in Quang Tri, Vietnam. 